\title{
Potencial turístico de un destino: una mirada al desarrollo y evolución. Caso: Santo Domingo, Ecuador
}

Tourist Potential of a Destination: A Look at Development and Evolution. Case: Santo Domingo, Ecuador

Potencial turístico de um destino: um olhar para o desenvolvimento e a evolução. Caso: Santo Domingo, Equador

Ana Verónica Reza Segovia

Pontificia Universidad Católica del Ecuador, Ecuador

rsav@pucesd.edu.ec https://orcid.org/0000-0002-1707-3930

Jenny Mabel Villarroel Noboa

Pontificia Universidad Católica del Ecuador, Ecuador

vnjm@pucesd.edu.ec https://orcid.org/0000-0003-3740-0641

Julieta Johanna Sánchez Mendoza Pontificia Universidad Católica del Ecuador, Ecuador smjj@pucesd.edu.ec https://orcid.org/0000-0001-8548-7302

José Marcelino Romero Gutiérrez Pontificia Universidad Católica del Ecuador, Ecuador rgjm@pucesd.edu.ec https://orcid.org/0000-0001-5351-2593 


\section{Revista Iberoamericana \\ de las Ciencias Sociales y \\ Humanísticas}

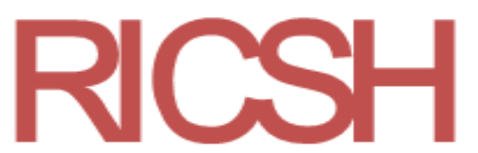

ISSN: 2395 - 7972

\section{Resumen}

El objetivo del presente estudio es identificar el potencial turístico de Santo Domingo, Ecuador, mediante el análisis de sus actividades turísticas y determinar los elementos del sistema turístico de la ciudad. Se trata de una investigación de alcance exploratorio descriptivo, con un diseño no experimental transversal. Metodológicamente, está basada en el trabajo de Sergio Molina (2000). Entre los resultados, destaca el incremento de 82 actividades turísticas en el 2019, de las cuales 74 están direccionadas al área de alimentos y bebidas. En este rubro, hay dos importantes zonas gastronómicas: una en la avenida La Lorena, con 28 establecimientos; otra en la avenida Venezuela, con un total de 26 establecimientos. En total, cuenta con 86 atractivos turísticos, posee servicios básicos, atención médica pública y privada, servicio de transporte y avenidas transitables. Además, la realización de eventos es un plus de desarrollo, ya que se estima que se realizan 1754 eventos por año en 14 establecimientos (entre hoteles, universidades y asociaciones). En conclusión, la existencia de actividades turísticas en Santo Domingo permite al visitante referir la zona y generar un incremento en la demanda. Las agencias operadoras de turismo deben enfatizar el diseño de paquetes y centrarse en dar a conocer los productos locales.

Palabras clave: atractivos turísticos, paquetes turísticos, potencialidades turísticas, productos gastronómicos.

\section{Abstract}

The objective of this study is to identify the tourism potential of Santo Domingo, Ecuador, by analyzing its tourism activities and determining the elements of the city's tourism system. It is a descriptive exploratory research, with a non-experimental cross-sectional design. Methodologically, it is based on the work of Sergio Molina (2000). Among the results, the increase of 82 tourist activities in 2019 stands out, of which 74 are directed to the area of food and beverages. In this area, there are two important gastronomic areas: one on La Lorena avenue, with 28 establishments; another on Venezuela avenue, with a total of 26 establishments. In total, it has 86 tourist attractions, has basic services, public and private medical care, transportation service and passable avenues. In addition, holding events is a development plus, since it is estimated that 1754 events are held per year in 14 establishments between hotels, universities and associations. In conclusion, the existence of tourist activities in Santo Domingo allows the visitor to refer to the area and generate an increase in demand. 


\section{Revista Iberoamericana \\ de las Ciencias Sociales y \\ Humanísticas}

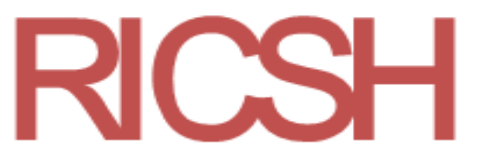

ISSN: 2395 - 7972

Tourism operating agencies should emphasize package design by focusing on publicizing local products.

Keywords: tourist attractions, tourist packages, tourist potential, gastronomic products.

\section{Resumo}

O objetivo deste estudo é identificar o potencial turístico de Santo Domingo, Equador, por meio da análise de sua atividade turística e da determinação dos elementos do sistema turístico da cidade. Trata-se de uma pesquisa exploratória descritiva, com delineamento transversal não experimental. Metodologicamente, baseia-se no trabalho de Sergio Molina (2000). Entre os resultados, destaca-se o aumento de 82 atividades turísticas em 2019, das quais 74 são direcionadas à área de alimentos e bebidas. Nesta área, existem dois importantes espaços gastronômicos: um na avenida La Lorena, com 28 estabelecimentos; outro na avenida Venezuela, com um total de 26 estabelecimentos. No total, são 86 atrativos turísticos, conta com serviços básicos, assistência médica pública e privada, serviço de transporte e avenidas transitáveis. Além disso, a realização de eventos é um diferencial em desenvolvimento, já que se estima que sejam realizados 1.754 eventos por ano em 14 estabelecimentos (entre hotéis, universidades e associações). Em conclusão, a existência de atividades turísticas em Santo Domingo permite ao visitante referir-se à área e gerar um aumento da procura. As agências operadoras de turismo devem enfatizar o design da embalagem e se concentrar na divulgação dos produtos locais.

Palavras-chave: atrações turísticas, pacotes turísticos, potencial turístico, produtos gastronômicos.

Fecha Recepción: Marzo 2020

Fecha Aceptación: Diciembre 2020

\section{Introducción}

Existen varias definiciones de turismo. Según la Organización Mundial de Turismo [OMT] (2016), el turismo es un fenómeno social, cultural y económico relacionado con el ocio y con el desplazamiento de personas a diversos lugares fuera de su residencia habitual. Es una actividad del sector terciario que aporta a la economía a nivel mundial mediante la generación de empleos directos e indirectos, aprovechando los recursos naturales y culturales que posee un territorio. 


\section{Revista Iberoamericana \\ de las Ciencias Sociales y \\ Humanísticas}

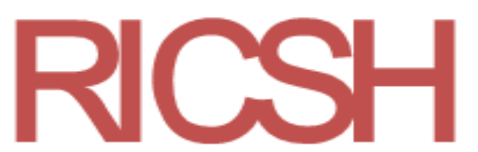

ISSN: 2395 - 7972

Para Hortua (2011), el turismo está ligado con la urbanización de una ciudad o territorio, ya que se presentan espacios destinados al consumo recreativo. Toda ciudad responde a la evolución de los mercados turísticos y trata de cumplir con las expectativas de la demanda. Es una actividad recreativa en la cultura del consumo.

La OMT (13 de febrero de 2019) indica que los interlocutores locales juegan un papel predominante; su colaboración e implicación hace que el turismo a pie permita que residentes y turistas compartan bienes comunes; para que no sucedan conflictos de intereses se requiere acceso a formación e incluir en la cadena de valor a la población local con la finalidad de que las nuevas oportunidades de negocio sean aprovechadas.

Según Molina (2000), el desarrollo de un territorio implica contar con un sistema turístico en el que cada elemento tribute a la consecución de un impacto positivo que posicione a la ciudad como un lugar propicio para la ejecución de actividades turísticas.

Un destino turístico es el resultado de varios procesos, condiciones sociales, económicas y culturales, sin dejar de lado los elementos directamente ligados al desarrollo de la actividad turística, tal y como los proveedores del servicio y los visitantes/turistas. Molina (2000) identifica seis elementos de los que dependerá la potencialidad turística de un determinado sector:

1) Los atractivos turísticos que posee un territorio, pueden ser naturales y culturales. Estos sitios deben despertar el interés del viajero para conocer su historia, ya que poseen características tangibles e intangibles.

2) La supraestructura, conformada por las entidades públicas y privadas que representan a los prestadores de servicios, así como de políticas que velan por los intereses de estos.

3) La infraestructura, dotada de viabilidad y puntos de conexión entre los diversos sectores turísticos.

4) Los servicios con los que cuenta una ciudad. Aquí se incluyen aquellos servicios que se relacionan directamente con el turista y los que evidencian una relación indirecta que son propias de un complemento turístico.

5) La demanda, integrada por los turistas visitantes del sector.

6) La comunidad receptora, conformada por los prestadores de servicios turísticos y los habitantes del sector. 


\section{Revista Iberoamericana \\ de las Ciencias Sociales y \\ Humanísticas}

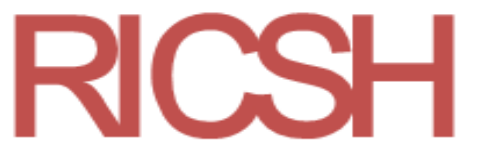

ISSN: $2395-7972$

Rivas y Magadán (2012), por su parte, mencionan que el desarrollo integral de los destinos turísticos depende de las relaciones establecidas entre los visitantes y la comunidad receptora. El impacto sociocultural se determina a partir del intercambio de costumbres, comportamientos, estilos de vida, valores éticos y morales. Así, para que un sitio cristalice su potencial turístico, es necesario anticipar y desarrollar alternativas de solución para cualquier tipo de desavenencia entre el residente y el visitante. Normalmente, cuando se identifica un sitio turístico, la comunidad receptora está presta a colaborar en todo lo que esté a su alcance para hallar una opción de desarrollo social-económico. Sin embargo, una vez consolidado el espacio turístico e identificadas las oportunidades de negocio, si no se obtienen los niveles de ingresos esperados, la sociedad podría retirar su apoyo y llegar a culpar a los turistas. Así pues, es importante recalcar que el equilibrio existente entre los residentes y visitantes dependerá del éxito del destino turístico.

A decir de Mikery y Pérez (2014), el sentido etimológico de potencial alude a un agente de poder, por un lado, y a lo que existe en un territorio y la aptitud o vocación de un espacio turístico, considerándose la suma de recursos que posee. Para determinar el potencial de un territorio es necesario emplear métodos que permitan valorar los recursos y atractivos. Dicha valoración debe hacerse inventariando los atractivos reales y potenciales, jerarquizando a cada uno de los elementos y tomando en cuenta el grado de conservación, importancia y existencia de especies.

Según el Ministerio de Turismo de Ecuador (2017), la jerarquización de los atractivos turísticos se determina a partir de un inventario en donde se registran tanto sus atributos naturales y culturales como las oportunidades de crecimiento. Esta valoración se lleva a cabo en dos etapas. La etapa uno consiste en el levantamiento, registro (objetos, lugares, acontecimientos, fenómenos, elementos de interés turísticos) y clasificación de los atractivos (categoría, tipo y subtipo). Aquí la información se obtiene mediante trabajo de campo. Mientras que en la etapa dos los atractivos se someten a los criterios de competitividad turística (accesibilidad y conectividad, planta turística, servicios, actividades que se practican, estado de conservación e integración, entorno, políticas y regulaciones, salud e higiene, seguridad turística) y a los criterios relacionados con la demanda (tipo de visitante y afluencia, difusión). Una vez valorados los atractivos, según el resultado de la ponderación, se presentan en una escala del I al IV; cada escalafón corresponde a un proceso de cualificación. 


\section{Revista Iberoamericana \\ de las Ciencias Sociales y \\ Humanísticas}

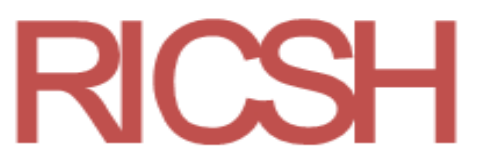

ISSN: $2395-7972$

Vincular a las actividades productivas y turísticas es una estrategia que busca mejorar las condiciones de vida de los habitantes de un determinado sector. Como es bien sabido, existe una constante expansión y diversificación del turismo debido a que el visitante tiene múltiples motivaciones y preferencias derivadas del turismo convencional y de la naturaleza (Mikery y Perez, 2014). Según Rivas y Magadán (2012), al identificar las potencialidades y recursos de un determinado sector, se deben evidenciar las ventajas y desventajas que la demanda turística trae consigo. También se debe analizar de forma técnica y metodológica la aplicación de estrategias, identificar las tendencias del turismo mundial y regional y realizar una proyección según la capacidad de respuesta a las exigencias y necesidades del turista con la aplicación de políticas de marketing y comercialización turística.

De acuerdo con Porter (citado en Blacutt, 2013), el desarrollo de una ciudad con menor o bajo nivel de adelanto requiere de la implementación de ventajas competitivas que promuevan el progreso en aspectos relacionados con la localización estratégica, la potencial demanda local no explotada, la integración de clústeres regionales y los recursos humanos. Sin embargo, Osorio y Domínguez (2019) indican que el progreso de un producto turístico no depende solo de su potencialidad como tal, sino también de las nociones y prácticas de sus actores y de la sinergia con su espacio. En efecto, tal y como apuntan Brinckmann y Wildgen (2003), si el turismo no se relacionara con la vida, no se necesitaría entender el comportamiento social: la práctica del turismo conlleva a sentir sus efectos en la concepción de la identidad y la sociedad como tal.

Las actividades turísticas relacionadas con la prestación de servicios de alimentos y bebidas son capaces de determinar una cultura, como lo afirman Acle y Montiel (2018). El arte culinario está conformado por el conjunto de conocimientos y actividades relacionadas con la elaboración de los alimentos propios de la cultura de un pueblo. Muchas veces determina el estilo de vida de una población. Sin duda, la importancia de la gastronomía radica en que es un fiel reflejo de la cultura de un pueblo. En la cocina se involucran la forma

de vida y el aprovechamiento de los recursos, entre otros elementos, por lo que es en sí misma un atractivo turístico.

En su investigación sobre el turismo gastronómico en Mealhada, Portugal, Oliveira (2011) concluye que existe una profunda relación entre la gastronomía y el turismo, el excursionismo está ligado a la gastronomía, por lo que es un factor del cual la economía depende en gran medida. 


\section{Revista Iberoamericana \\ de las Ciencias Sociales y \\ Humanísticas}

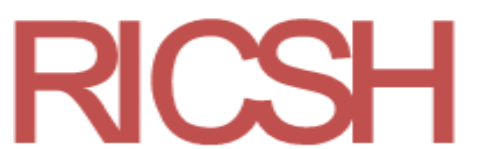

ISSN: 2395 - 7972

Una analogía interesante respecto al turismo y la valía que este tiene la aporta Velarde (2015). Este autor menciona que conocer a las poblaciones es igual que conocer a los hijos: quien está cerca no se da cuenta de cómo crecen, el visitante aprecia mejor el progreso de un determinado lugar.

Ahora bien, la ciudad de Santo Domingo de los Colorados está ubicada en la provincia de Santo Domingo de los Tsáchilas, en la República del Ecuador. Situada en los flancos extremos de la cordillera de los Andes, forma parte de la región Costa y cuenta con una superficie de $3757 \mathrm{~km}^{2}$. Santo Domingo de los Colorados es conocida como una ciudad de paso; no se ha posicionado como un destino turístico a pesar de contar con muchos atractivos naturales y culturales, una gran variedad de actividades turísticas y una amplia oferta gastronómica.

Teniendo en cuenta todo lo anterior, se plantearon las siguientes preguntas de investigación:

- ¿Cuáles son las actividades turísticas que se desarrollan en Santo Domingo?

- ¿Cuáles son los elementos del sistema turístico determinantes para consolidarse como un sitio preferencial para hacer turismo?

Consecuentemente, los objetivos del presente estudio se plantearon en los siguientes términos:

- Identificar el potencial turístico existente en Santo Domingo mediante el análisis de sus actividades turísticas.

- Determinar los elementos del sistema turístico aplicando la metodología de Sergio Molina (2000).

\section{Metodología}

El estudio se realizó mediante un diseño no experimental transversal, con el fin de identificar las características de la realidad de Santo Domingo y su relación con el turismo. Además, al ser un tema poco estudiado, es de alcance exploratorio descriptivo.

Cabe señalar que se toma como referencia, en primer lugar, los resultados de la encuesta aplicada por Zhizpón (2017), quien encontró que los turistas prefieren visitar Santo Domingo en época de feriados y que la diversión y la naturaleza son dos de los principales motivos para visitar un destino turístico, entre otros hallazgos. Y, en segundo lugar, los resultados de la investigación de campo realizada por Moreno y Valdivieso (2017), quienes 


\section{Revista Iberoamericana \\ de las Ciencias Sociales y \\ Humanísticas}

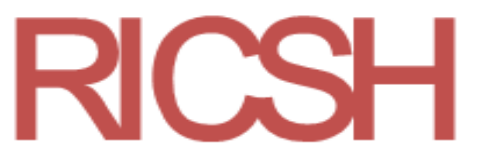

ISSN: 2395 - 7972

determinaron que los turistas llegan a Santo Domingo para visitar los sitios naturales y disfrutar de su gastronomía.

En cuanto a la estadística de actividades turísticas, se toma como principal fuente el catastro del Ministerio de Turismo (2019), que permite identificar la evolución año con año de dichas actividades. Por último, los elementos del sistema turístico de Santo Domingo se determinan según la metodología de Molina (2000).

\section{Resultados}

\section{Identificar el potencial turístico existente en Santo Domingo mediante el análisis de sus actividades turísticas}

El potencial turístico se determina por la forma en que la oferta de productos y servicios logra satisfacer a una demanda. El artículo 5 de la Ley de Turismo del Ecuador (Congreso Nacional, 29 de diciembre de 2014) determina lo siguiente:

Se consideran actividades turísticas las desarrolladas por personas naturales o jurídicas que se dediquen a la prestación remunerada de modo habitual a una o más de las siguientes actividades:

a) Alojamiento;

b) Servicio de alimentos y bebidas;

c) Transportación, cuando se dedica principalmente al turismo; inclusive el transporte aéreo, marítimo, fluvial, terrestre y el alquiler de vehículos para este propósito;

d) Operación, cuando las agencias de viajes provean su propio transporte, esa actividad se considerará parte del agenciamiento;

e) La de intermediación, agencia de servicios turísticos y organizadoras de eventos, congresos y convenciones.

A partir del análisis de las actividades turísticas existentes en Santo Domingo, se encontró que desde el año 2015 hasta el 2019 se ha incrementado año con año el abanico de opciones encaminadas a este fin como se evidencia en la tabla 1. El mayor incremento se dio en el 2019, cuando 82 actividades se sumaron a la oferta turística, de las cuales 74 estuvieron destinadas al servicio de alimentos y bebidas para el año 2019. Considerando que Santo Domingo es un punto de conexión entre la sierra y la costa, pobladores de distintas partes de 


\section{Revista Iberoamericana \\ de las Ciencias Sociales y \\ Humanísticas}

ISSN: $2395-7972$

la región ecuatoriana se han asentado ahí, junto con las distintas costumbres gastronómicas de sus lugares de origen, lo que ha expandido la variedad de sabores del lugar.

Tabla 1. Actividades turísticas de Santo Domingo

\begin{tabular}{|l|l|l|l|l|l|}
\hline Actividades turísticas & 2019 & 2018 & 2017 & 2016 & 2015 \\
\hline Alimentos y bebidas & 74 & 4 & 11 & 20 & 11 \\
\hline Alojamiento & 2 & 4 & 1 & 2 & 2 \\
\hline Operación e intermediación & 3 & 6 & 2 & 2 & 3 \\
\hline Parques y atracciones estables & 3 & 1 & 1 & 2 & 7 \\
\hline Total & 82 & 15 & 15 & 26 & 23 \\
\hline
\end{tabular}

Fuente: Ministerio de Turismo (2019)

Calle (2019) identifica un importante sector referencial de alimentos y bebidas ubicado en la avenida La Lorena, con 28 establecimientos (ocho de comida tradicional, siete de mariscos, cinco de asados y ocho de comida rápida). Mientras que Quirola (2019) menciona que otro sector importante de expendio de alimentos es el distribuido a lo largo de la avenida Venezuela, con un total de 26 establecimientos (15 de comida rápida, dos de mariscos, dos de asados y horneados, dos de comida italiana, uno de comida árabe, uno de comida mexicana, uno de comida china, uno de comida tradicional y una cafetería).

\section{Determinar los elementos del sistema turístico aplicando la metodología de Sergio Molina}

Uno de los pasos del sistema turístico propuesto por Molina (2000) es identificar los atractivos turísticos que posee un territorio. Santo Domingo cuenta con 86 atractivos turísticos inventariados, como se evidencia en la tabla 2. Es importante considerar su jerarquía, ya que de este modo se evidencia la relevancia y el nivel de atracción que posee cada recurso. Según lo indicado por el Ministerio de Turismo del Ecuador (2017), que sigue los criterios de la Organización de Estados Americanos (OEA), en la jerarquía IV se posicionan a aquellos atractivos excepcionales de alto significado en el mercado turístico internacional; la jerarquía III aglutina a los atractivos con rasgos excepcionales, puede motivar a ser visitado de forma individual o en conjunto con otros atractivos cercanos; la jerarquía II pretende identificar a atractivos con algún rasgo llamativo que genere interés a 


\section{Revista Iberoamericana \\ de las Ciencias Sociales y \\ Humanísticas}

ISSN: $2395-7972$

visitantes, y la jerarquía I identifica a atractivos que no tienen méritos suficientes para ser considerados en una jerarquía superior.

Santo Domingo cuenta con seis atractivos de jerarquía III, ya que estos despiertan un alto grado de interés en el turista, son lugares característicos de la cultura propia de la zona y pueden ser visitados en familia. De jerarquía II existen 48 atractivos que generan al turista interés por visitarlos.

Tabla 2. Atractivos turísticos de Santo Domingo

\begin{tabular}{|c|c|c|c|c|c|}
\hline Núm. & Nombre del atractivo & Jerarquía & Categoría & Tipo & Subtipo \\
\hline 1 & Río Damas & II & $\begin{array}{l}\text { Atractivos } \\
\text { naturales }\end{array}$ & Ríos & Rio \\
\hline 2 & Bosque Tinalandia & II & $\begin{array}{l}\text { Atractivos } \\
\text { naturales }\end{array}$ & Bosques & Húmedo \\
\hline 3 & Río Lelia & I & $\begin{array}{l}\text { Atractivos } \\
\text { naturales }\end{array}$ & Ríos & Río \\
\hline 4 & Blue Point Flowers & II & $\begin{array}{l}\text { Manifestaciones } \\
\text { culturales }\end{array}$ & $\begin{array}{l}\text { Realizaciones } \\
\text { técnicas } \\
\text { científicas }\end{array}$ & $\begin{array}{l}\text { Explotaciones } \\
\text { agropecuarias } \\
\text { y pesqueras }\end{array}$ \\
\hline 5 & Cascadas del Diablo & II & $\begin{array}{l}\text { Atractivos } \\
\text { naturales }\end{array}$ & Ríos & Cascadas \\
\hline 6 & Cascada Chorrera del Napa & I & $\begin{array}{l}\text { Atractivos } \\
\text { naturales }\end{array}$ & Ríos & Cascadas \\
\hline 7 & Río Meme & I & $\begin{array}{l}\text { Atractivos } \\
\text { naturales }\end{array}$ & Ríos & Río \\
\hline 8 & Río Toachi & I & $\begin{array}{l}\text { Atractivos } \\
\text { naturales }\end{array}$ & Ríos & Río \\
\hline 9 & $\begin{array}{l}\text { Laguna La Totora-Chitoa } \\
\text { Alto }\end{array}$ & I & $\begin{array}{l}\text { Atractivos } \\
\text { naturales }\end{array}$ & $\begin{array}{l}\text { Ambientes } \\
\text { lacustres }\end{array}$ & Laguna \\
\hline 10 & $\begin{array}{l}\text { Rancho Las Marías } \\
\text { (productos lácteos) }\end{array}$ & II & $\begin{array}{l}\text { Manifestaciones } \\
\text { culturales }\end{array}$ & $\begin{array}{l}\text { Realizaciones } \\
\text { técnicas y } \\
\text { científicas }\end{array}$ & $\begin{array}{l}\text { Explotaciones } \\
\text { industriales }\end{array}$ \\
\hline
\end{tabular}


Revista Iberoamericana

de las Ciencias Sociales y

Humanísticas

ISSN: $2395-7972$

\begin{tabular}{|c|c|c|c|c|c|}
\hline 11 & Río Bolo & I & $\begin{array}{l}\text { Atractivos } \\
\text { naturales }\end{array}$ & Ríos & Río \\
\hline 12 & Cascadas de Cristal & I & $\begin{array}{l}\text { Atractivos } \\
\text { naturales }\end{array}$ & Ríos & Cascadas \\
\hline 13 & Río Baba & I & $\begin{array}{l}\text { Atractivos } \\
\text { naturales }\end{array}$ & Ríos & Río \\
\hline 14 & Malecón El Esfuerzo & $\mathrm{I}$ & $\begin{array}{l}\text { Manifestaciones } \\
\text { culturales }\end{array}$ & Arquitectura & $\begin{array}{l}\text { Espacio } \\
\text { público }\end{array}$ \\
\hline 15 & $\begin{array}{l}\text { Cascadas Las Rocas- } \\
\text { Polanco }\end{array}$ & $\mathrm{I}$ & $\begin{array}{l}\text { Atractivos } \\
\text { naturales }\end{array}$ & Ríos & Cascada \\
\hline 16 & Centro Cultural Du Tenka & III & $\begin{array}{l}\text { Manifestaciones } \\
\text { culturales }\end{array}$ & Folklore & $\begin{array}{l}\text { Pueblo y/o } \\
\text { nacionalidad } \\
\text { etnográfica }\end{array}$ \\
\hline 17 & Río Salgana-Poza Azul & $\mathrm{I}$ & $\begin{array}{l}\text { Atractivos } \\
\text { naturales }\end{array}$ & Ríos & Río \\
\hline 18 & $\begin{array}{l}\text { Finca Agroecológica la } \\
\text { Floreana }\end{array}$ & II & $\begin{array}{l}\text { Manifestaciones } \\
\text { culturales }\end{array}$ & $\begin{array}{l}\text { Realizaciones } \\
\text { técnicas y } \\
\text { científicas }\end{array}$ & $\begin{array}{l}\text { Explotaciones } \\
\text { agropecuarias } \\
\text { y pesqueras }\end{array}$ \\
\hline 19 & $\begin{array}{l}\text { Reserva Ecológica Santa } \\
\text { Rosa }\end{array}$ & I & $\begin{array}{l}\text { Atractivos } \\
\text { naturales }\end{array}$ & Bosques & Húmedo \\
\hline 20 & Río Cupipe & I & $\begin{array}{l}\text { Atractivos } \\
\text { naturales }\end{array}$ & Río & Río \\
\hline 21 & Iglesia Jesús del Gran Poder & II & $\begin{array}{l}\text { Manifestaciones } \\
\text { culturales }\end{array}$ & Arquitectura & $\begin{array}{l}\text { Histórica(civil, } \\
\text { religiosa, } \\
\text { militar y } \\
\text { vernácula) }\end{array}$ \\
\hline 22 & $\begin{array}{l}\text { Grupo cultural Mosco } \\
\text { Bolón (grupo de jóvenes) }\end{array}$ & II & $\begin{array}{l}\text { Manifestaciones } \\
\text { culturales }\end{array}$ & Folklore & $\begin{array}{l}\text { Música y } \\
\text { danza }\end{array}$ \\
\hline 23 & Grupo cultural Sayama & II & $\begin{array}{l}\text { Manifestaciones } \\
\text { culturales }\end{array}$ & Folklore & $\begin{array}{l}\text { Música y } \\
\text { danza }\end{array}$ \\
\hline 24 & Cascada del Rosario & $\mathrm{I}$ & $\begin{array}{l}\text { Atractivos } \\
\text { naturales }\end{array}$ & Ríos & Río \\
\hline
\end{tabular}


Revista Iberoamericana

de las Ciencias Sociales y

Humanísticas

ISSN: 2395 - 7972

\begin{tabular}{|c|c|c|c|c|c|}
\hline 25 & Río Sandima & I & $\begin{array}{l}\text { Atractivos } \\
\text { naturales }\end{array}$ & Rios & Río \\
\hline 26 & $\begin{array}{l}\text { Centro Cultural Masara } \\
\text { Mudu }\end{array}$ & II & $\begin{array}{l}\text { Manifestaciones } \\
\text { culturales }\end{array}$ & Folklore & $\begin{array}{l}\text { Pueblo y/o } \\
\text { nacionalidad } \\
\text { etnográfica }\end{array}$ \\
\hline 27 & $\begin{array}{l}\text { Unión de ríos Peripa y } \\
\text { Tasugua }\end{array}$ & I & $\begin{array}{l}\text { Atractivos } \\
\text { naturales }\end{array}$ & Ríos & Cascada \\
\hline 28 & Cascada Merizalde & $\mathrm{I}$ & $\begin{array}{l}\text { Atractivos } \\
\text { naturales }\end{array}$ & Ríos & Cascada \\
\hline 29 & Cascada San Rafael & I & $\begin{array}{l}\text { Atractivos } \\
\text { naturales }\end{array}$ & Ríos & Cascada \\
\hline 30 & Cascada Semantes & I & $\begin{array}{l}\text { Atractivos } \\
\text { naturales }\end{array}$ & Ríos & Cascada \\
\hline 31 & Cascada El Imán & $\mathrm{I}$ & $\begin{array}{l}\text { Atractivos } \\
\text { naturales }\end{array}$ & Ríos & Cascada \\
\hline 32 & Cascada Salto del Bimbe & $\mathrm{I}$ & $\begin{array}{l}\text { Atractivos } \\
\text { naturales }\end{array}$ & Ríos & Cascada \\
\hline 33 & Monolitos Tsáchilas & $\mathrm{I}$ & $\begin{array}{l}\text { Manifestaciones } \\
\text { culturales }\end{array}$ & Arquitectura & $\begin{array}{l}\text { Área } \\
\text { patrimonial / } \\
\text { arqueológica }\end{array}$ \\
\hline 34 & $\begin{array}{l}\text { Iglesia Ascención de Santo } \\
\text { Domingo }\end{array}$ & II & $\begin{array}{l}\text { Manifestaciones } \\
\text { culturales }\end{array}$ & Arquitectura & $\begin{array}{l}\text { Histórica } \\
\text { (civil, } \\
\text { religiosa, } \\
\text { militar y } \\
\text { vernácula) }\end{array}$ \\
\hline 35 & $\begin{array}{l}\text { Monumento Familia } \\
\text { Tsáchila }\end{array}$ & II & $\begin{array}{l}\text { Manifestaciones } \\
\text { culturales }\end{array}$ & Arquitectura & Monumentos \\
\hline 36 & $\begin{array}{l}\text { Monumento Joaquín } \\
\text { Zaracay }\end{array}$ & II & $\begin{array}{l}\text { Manifestaciones } \\
\text { culturales }\end{array}$ & Arquitectura & Monumentos \\
\hline 37 & Monumento Julio Jaramillo & II & $\begin{array}{l}\text { Manifestaciones } \\
\text { culturales }\end{array}$ & Arquitectura & Monumentos \\
\hline
\end{tabular}


Revista Iberoamericana

de las Ciencias Sociales y

Humanísticas

ISSN: 2395 - 7972

\begin{tabular}{|c|c|c|c|c|c|}
\hline 38 & Parque Zaracay & II & $\begin{array}{l}\text { Manifestaciones } \\
\text { culturales }\end{array}$ & Arquitectura & $\begin{array}{l}\text { Espacio } \\
\text { público }\end{array}$ \\
\hline 39 & Monumento a la Madre & II & $\begin{array}{l}\text { Manifestaciones } \\
\text { culturales }\end{array}$ & Arquitectura & Monumentos \\
\hline 40 & Parque a la Madre & II & $\begin{array}{l}\text { Manifestaciones } \\
\text { culturales }\end{array}$ & Arquitectura & $\begin{array}{l}\text { Espacio } \\
\text { público }\end{array}$ \\
\hline 41 & Parque Ecológico & II & $\begin{array}{l}\text { Manifestaciones } \\
\text { culturales }\end{array}$ & Arquitectura & $\begin{array}{l}\text { Espacio } \\
\text { público }\end{array}$ \\
\hline 42 & Casa Diocesana Santa Rosa & II & $\begin{array}{l}\text { Manifestaciones } \\
\text { culturales }\end{array}$ & Arquitectura & $\begin{array}{l}\text { Histórica } \\
\text { (civil, } \\
\text { religiosa, } \\
\text { militar y } \\
\text { vernácula) }\end{array}$ \\
\hline 43 & $\begin{array}{l}\text { Iglesia Catedral El Buen } \\
\text { Pastor }\end{array}$ & II & $\begin{array}{l}\text { Manifestaciones } \\
\text { culturales }\end{array}$ & Arquitectura & $\begin{array}{l}\text { Histórica } \\
\text { (civil, } \\
\text { religiosa, } \\
\text { militar y } \\
\text { vernácula) }\end{array}$ \\
\hline 44 & Monumento Las Reinas & II & $\begin{array}{l}\text { Manifestaciones } \\
\text { culturales }\end{array}$ & Arquitectura & Monumentos \\
\hline 45 & Monumento Indio Colorado & II & $\begin{array}{l}\text { Manifestaciones } \\
\text { culturales }\end{array}$ & Arquitectura & Monumentos \\
\hline 46 & $\begin{array}{l}\text { Monumento Sueño de } \\
\text { Bolívar }\end{array}$ & II & $\begin{array}{l}\text { Manifestaciones } \\
\text { culturales }\end{array}$ & Arquitectura & Monumentos \\
\hline 47 & $\begin{array}{l}\text { Parque Ecológico Cerro } \\
\text { Bombolí }\end{array}$ & II & $\begin{array}{l}\text { Manifestaciones } \\
\text { culturales }\end{array}$ & Arquitectura & $\begin{array}{l}\text { Espacio } \\
\text { público }\end{array}$ \\
\hline 48 & Parque Intergeneracional & II & $\begin{array}{l}\text { Manifestaciones } \\
\text { culturales }\end{array}$ & Arquitectura & $\begin{array}{l}\text { Espacio } \\
\text { público }\end{array}$ \\
\hline 49 & Parque Julio Marrero & III & $\begin{array}{l}\text { Manifestaciones } \\
\text { culturales }\end{array}$ & $\begin{array}{l}\text { Realizaciones } \\
\text { técnicas y } \\
\text { científicas }\end{array}$ & $\begin{array}{l}\text { Centro de } \\
\text { exhibición de } \\
\text { flora y fauna }\end{array}$ \\
\hline
\end{tabular}


Revista Iberoamericana

de las Ciencias Sociales y

Humanísticas

ISSN: 2395 - 7972

\begin{tabular}{|c|c|c|c|c|c|}
\hline 50 & Bioparque Kasama & II & $\begin{array}{l}\text { Manifestaciones } \\
\text { culturales }\end{array}$ & $\begin{array}{l}\text { Realizaciones } \\
\text { técnicas y } \\
\text { científicas }\end{array}$ & $\begin{array}{l}\text { Centro de } \\
\text { exhibición de } \\
\text { flora y fauna }\end{array}$ \\
\hline 51 & Monumento Pileta Pio XII & II & $\begin{array}{l}\text { Manifestaciones } \\
\text { culturales }\end{array}$ & Arquitectura & Monumentos \\
\hline 52 & $\begin{array}{l}\text { Parque de la Juventud y la } \\
\text { Familia }\end{array}$ & II & $\begin{array}{l}\text { Manifestaciones } \\
\text { culturales }\end{array}$ & Arquitectura & $\begin{array}{l}\text { Espacio } \\
\text { público }\end{array}$ \\
\hline 53 & Monumento al Colono & II & $\begin{array}{l}\text { Manifestaciones } \\
\text { culturales }\end{array}$ & Arquitectura & Monumentos \\
\hline 54 & $\begin{array}{l}\text { Monumento a la Virgen del } \\
\text { Rosario }\end{array}$ & II & $\begin{array}{l}\text { Manifestaciones } \\
\text { culturales }\end{array}$ & Arquitectura & Monumentos \\
\hline 55 & $\begin{array}{l}\text { Parque Etnobotánico } \\
\text { Mariano Chanchán }\end{array}$ & II & $\begin{array}{l}\text { Manifestaciones } \\
\text { culturales }\end{array}$ & $\begin{array}{l}\text { Realizaciones } \\
\text { técnicas y } \\
\text { científicas }\end{array}$ & $\begin{array}{l}\text { Centro de } \\
\text { exhibición de } \\
\text { flora y fauna }\end{array}$ \\
\hline 56 & Círculo de los Continentes & II & $\begin{array}{l}\text { Manifestaciones } \\
\text { culturales }\end{array}$ & Arquitectura & $\begin{array}{l}\text { Espacio } \\
\text { público }\end{array}$ \\
\hline 57 & $\begin{array}{l}\text { Recinto Ferial Dr. Alfonso } \\
\text { Torres Ordoñez }\end{array}$ & III & $\begin{array}{l}\text { Manifestaciones } \\
\text { culturales }\end{array}$ & $\begin{array}{l}\text { Acontecimie } \\
\text { ntos } \\
\text { programados }\end{array}$ & $\begin{array}{l}\text { Convenciones, } \\
\text { ferias (no } \\
\text { artesanales)y } \\
\text { congresos }\end{array}$ \\
\hline 58 & $\begin{array}{l}\text { Monumento Monseñor } \\
\text { Emilio Stehle }\end{array}$ & II & $\begin{array}{l}\text { Manifestaciones } \\
\text { culturales }\end{array}$ & Arquitectura & Monumentos \\
\hline 59 & $\begin{array}{l}\text { Monumento Resiliencia y } \\
\text { Nuevos Mercados del Arte }\end{array}$ & II & $\begin{array}{l}\text { Manifestaciones } \\
\text { culturales }\end{array}$ & Arquitectura & Monumentos \\
\hline 60 & $\begin{array}{l}\text { Parque Lineal Manuel } \\
\text { Ramos }\end{array}$ & II & $\begin{array}{l}\text { Manifestaciones } \\
\text { culturales }\end{array}$ & Arquitectura & $\begin{array}{l}\text { Espacio } \\
\text { público }\end{array}$ \\
\hline 61 & Recinto Ferial Chilachitó & II & $\begin{array}{l}\text { Manifestaciones } \\
\text { culturales }\end{array}$ & $\begin{array}{l}\text { Acontecimie } \\
\text { ntos } \\
\text { programados }\end{array}$ & $\begin{array}{l}\text { Convenciones, } \\
\text { ferias(no } \\
\text { artesanales)y } \\
\text { congresos }\end{array}$ \\
\hline
\end{tabular}


Revista Iberoamericana

de las Ciencias Sociales y

Humanísticas

ISSN: $2395-7972$

\begin{tabular}{|c|c|c|c|c|c|}
\hline 62 & $\begin{array}{l}\text { Centro Turístico Aldea } \\
\text { Colorada }\end{array}$ & II & $\begin{array}{l}\text { Manifestaciones } \\
\text { culturales }\end{array}$ & Folklore & $\begin{array}{l}\text { Pueblo y/o } \\
\text { nacionalidad } \\
\text { etnográfica }\end{array}$ \\
\hline 63 & Comuna El Poste & III & $\begin{array}{l}\text { Manifestaciones } \\
\text { culturales }\end{array}$ & Folklore & $\begin{array}{l}\text { Pueblo y/o } \\
\text { nacionalidad } \\
\text { etnográfica }\end{array}$ \\
\hline 64 & Comuna de Chigüilpe & III & $\begin{array}{l}\text { Manifestaciones } \\
\text { culturales }\end{array}$ & Folklore & $\begin{array}{l}\text { Pueblo y/o } \\
\text { nacionalidad } \\
\text { etnográfica }\end{array}$ \\
\hline 65 & Malecón San Gabriel & $\mathrm{I}$ & $\begin{array}{l}\text { Manifestaciones } \\
\text { culturales }\end{array}$ & Arquitectura & $\begin{array}{l}\text { Espacio } \\
\text { público }\end{array}$ \\
\hline 66 & Zoológico Isla del Tapir & II & $\begin{array}{l}\text { Manifestaciones } \\
\text { culturales }\end{array}$ & $\begin{array}{l}\text { Realizaciones } \\
\text { técnicas y } \\
\text { científicas }\end{array}$ & $\begin{array}{l}\text { Centro de } \\
\text { exhibición de } \\
\text { flora y fauna }\end{array}$ \\
\hline 67 & $\begin{array}{l}\text { Iglesia Nuestra Señora del } \\
\text { Valle }\end{array}$ & II & $\begin{array}{l}\text { Manifestaciones } \\
\text { culturales }\end{array}$ & Arquitectura & $\begin{array}{l}\text { Histórica } \\
\text { (civil, } \\
\text { religiosa, } \\
\text { militar y } \\
\text { vernácula) }\end{array}$ \\
\hline 68 & $\begin{array}{l}\text { Finca Marianita } \\
\text { (elaboración de panela y } \\
\text { licores) }\end{array}$ & II & $\begin{array}{l}\text { Manifestaciones } \\
\text { culturales }\end{array}$ & $\begin{array}{l}\text { Realizaciones } \\
\text { técnicas y } \\
\text { científicas }\end{array}$ & $\begin{array}{l}\text { Explotaciones } \\
\text { agropecuarias } \\
\text { y pesqueras }\end{array}$ \\
\hline 69 & $\begin{array}{l}\text { Las Pompeyas (elaboración } \\
\text { artesanal de productos del } \\
\text { cacao) }\end{array}$ & II & $\begin{array}{l}\text { Manifestaciones } \\
\text { culturales }\end{array}$ & $\begin{array}{l}\text { Realizaciones } \\
\text { técnicas } \\
\text { científicas }\end{array}$ & $\begin{array}{l}\text { Explotaciones } \\
\text { agropecuarias } \\
\text { y pesqueras }\end{array}$ \\
\hline 70 & Quinta San Francisco & II & $\begin{array}{l}\text { Manifestaciones } \\
\text { culturales }\end{array}$ & $\begin{array}{l}\text { Realizaciones } \\
\text { técnicas } \\
\text { científicas }\end{array}$ & $\begin{array}{l}\text { Explotaciones } \\
\text { agropecuarias } \\
\text { y pesqueras }\end{array}$ \\
\hline 71 & Río Blanco & II & $\begin{array}{l}\text { Atractivos } \\
\text { naturales }\end{array}$ & Ríos & Río \\
\hline 72 & Playa de las Garzas & II & $\begin{array}{l}\text { Atractivos } \\
\text { naturales }\end{array}$ & Ríos & Playa de río \\
\hline
\end{tabular}


Revista Iberoamericana

de las Ciencias Sociales y

Humanísticas

ISSN: 2395 - 7972

\begin{tabular}{|c|c|c|c|c|c|}
\hline 73 & La Bocana & II & $\begin{array}{l}\text { Atractivos } \\
\text { naturales }\end{array}$ & Ríos & Río \\
\hline 74 & Río Cristal & I & $\begin{array}{l}\text { Atractivos } \\
\text { naturales }\end{array}$ & Ríos & Río \\
\hline 75 & Río Como Hacemos & $\mathrm{I}$ & $\begin{array}{l}\text { Atractivos } \\
\text { naturales }\end{array}$ & Ríos & Río \\
\hline 76 & Cascada La Chorrera & I & $\begin{array}{l}\text { Atractivos } \\
\text { naturales }\end{array}$ & Ríos & Río \\
\hline 77 & Tolas del Recinto Chiguilpe & II & $\begin{array}{l}\text { Manifestaciones } \\
\text { culturales }\end{array}$ & Arquitectura & $\begin{array}{l}\text { Área } \\
\text { patrimonial/arq } \\
\text { ueológica }\end{array}$ \\
\hline 78 & $\begin{array}{l}\text { Mishilick-Finca } \\
\text { agroecológica del Coronel }\end{array}$ & II & $\begin{array}{l}\text { Manifestaciones } \\
\text { culturales }\end{array}$ & $\begin{array}{l}\text { Realizaciones } \\
\text { técnicas } \\
\text { científicas }\end{array}$ & $\begin{array}{l}\text { Explotaciones } \\
\text { agropecuarias } \\
\text { y pesqueras }\end{array}$ \\
\hline 79 & $\begin{array}{l}\text { Fiesta del Kasama- Comuna } \\
\text { Colorados del Bua }\end{array}$ & II & $\begin{array}{l}\text { Manifestaciones } \\
\text { culturales }\end{array}$ & Folklore & $\begin{array}{l}\text { Manifestacione } \\
\text { s religiosas, } \\
\text { tradiciones y } \\
\text { creencias } \\
\text { populares }\end{array}$ \\
\hline 80 & $\begin{array}{l}\text { Centro comunitario Shinopi } \\
\text { Bolón Tsáchilas }\end{array}$ & III & $\begin{array}{l}\text { Manifestaciones } \\
\text { culturales }\end{array}$ & Folklore & $\begin{array}{l}\text { Pueblo o } \\
\text { nacionalidad } \\
\text { etnográfica }\end{array}$ \\
\hline 81 & Cascada Bella Vista & $\mathrm{I}$ & $\begin{array}{l}\text { Atractivos } \\
\text { naturales }\end{array}$ & Ríos & Cascadas \\
\hline 82 & Río Búa & $\mathrm{I}$ & $\begin{array}{l}\text { Atractivos } \\
\text { naturales }\end{array}$ & Ríos & Río \\
\hline 83 & Estero River & $\mathrm{I}$ & $\begin{array}{l}\text { Atractivos } \\
\text { naturales }\end{array}$ & Ríos & Río \\
\hline 84 & Río Ompechico & $\mathrm{I}$ & $\begin{array}{l}\text { Atractivos } \\
\text { naturales }\end{array}$ & Ríos & Río \\
\hline 85 & Río Chila & $\mathrm{I}$ & $\begin{array}{l}\text { Atractivos } \\
\text { naturales }\end{array}$ & Ríos & Río \\
\hline
\end{tabular}


Revista Iberoamericana

de las Ciencias Sociales y

Humanísticas

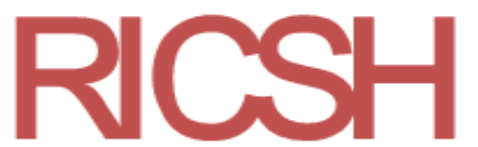

ISSN: $2395-7972$

\begin{tabular}{|c|l|l|l|l|l|}
\hline 86 & Río Soberano & I & $\begin{array}{l}\text { Atractivos } \\
\text { naturales }\end{array}$ & Ríos & Río \\
\hline
\end{tabular}

Fuente: Gobierno Autónomo Descentralizado de Santo Domingo (2017)

En relación con su infraestructura y los servicios básicos, Santo Domingo cuenta con el respaldo de la Empresa Pública Municipal de Agua Potable y Alcantarillado, gracias a lo cual $53.8 \%$ de agua llega por red dentro de las viviendas, mientras que $47.2 \%$ se abastece por medio de pozos profundos; en cuanto al servicio de alcantarillado, la población se encuentra abastecida en $70 \%$ y según los indicadores de red de alcantarillado, cubre 2017 kilómetros de tubería. La Corporación Eléctrica del Ecuador (CNEL) se encarga del abastecimiento de electricidad: $97 \%$ de la población de la ciudad dispone de energía eléctrica y alumbrado público. En cuanto al servicio de telefonía convencional, la Corporación Nacional de Telecomunicaciones (CNT) ofrece una cobertura de $33.9 \%$. Respecto a la telefonía móvil, varias empresas brindan servicio con una cobertura de $4 \mathrm{G}$ en la cabecera cantonal y un alcance de 82.40 \% de la población (Gobierno Autónomo Descentralizado de Santo Domingo, 2014).

Entre 1962 y 1965, se construyeron las principales carreteras que conectan a la provincia de Santo Domingo de los Tsáchilas. Entre las principales vías se encuentran AloagSanto Domingo, Santo Domingo-Esmeraldas, Santo Domingo-Manta, Santo DomingoGuayaquil, la E25, que atraviesa Los Ríos, Manabí y Esmeraldas, y la E20, que va hacia Pichincha. La ciudad posee una terminal terrestre interprovincial, con 45 empresas de transporte terrestre que se movilizan por todo el país; una miniterminal intercantonal responsables del traslado de turistas y visitantes, y en el área urbana se cuenta con cinco empresas de transporte que operan 31 rutas con 356 unidades.

Santo Domingo cuenta con los hospitales públicos Dr. Gustavo Domínguez, Hospital General de Santo Domingo, el Hospital del Instituto Ecuatoriano de Seguridad Social (IESS), Centro Ambulatorio IESS; 28 clínicas que pertenecen al sector privado; 140 consultorios particulares, entre clínicas y laboratorios médicos, y los centros de primer nivel el Circuito de Salud Agusto Egas y el Centro de Salud Los Rosales (Ministerio de Salud Pública, 2017).

En lo que respecta a la supraestructura, los entes reguladores del turismo son el Gobierno Autónomo Descentralizado del Municipio de Santo Domingo, Gobierno Autónomo Descentralizado de la Provincia, Ministerio de Turismo y la Cámara de Turismo. 


\section{Revista Iberoamericana \\ de las Ciencias Sociales y \\ Humanísticas}

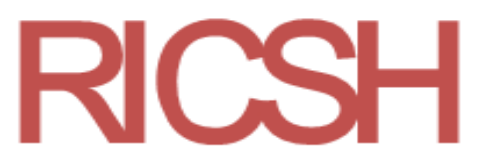

ISSN: 2395 - 7972

Estos organismos son los encargados de generar estrategias para dinamizar la economía en la ciudad y la provincia.

Para el 2010 (fecha del último censo realizado por el Instituto Nacional de Estadística y Censos [INEC]), la comunidad receptora de Santo Domingo era de 368013 habitantes: 183058 hombres y 184955 mujeres, con una proyección para el 2019 de 450694 habitantes (INEC, 2010).

En cuanto a la realización de eventos, según Castro y Valarezo (2019), en Santo Domingo se realizan 1754 eventos por año en 14 establecimientos que prestan este servicio. Dentro de las instalaciones de estos lugares se llevan a cabo conferencias, eventos sociales, culturales, capacitaciones, reuniones de trabajo, empresariales, talleres, congresos, conciertos, certámenes de belleza y eventos académicos. Los establecimientos cuentan con parqueadero privado, acceso para personas con discapacidad, servicios básicos, servicios adicionales, equipo de audio y video, iluminación y señalética reglamentaria. La capacidad de cada uno es la siguiente: Gran Hotel Santo Domingo (1610 personas), Hotel Toachi (1810 personas), Hotel Zaracay (720 personas), Hotel Golden Vista (60 personas); Pontificia Universidad Católica del Ecuador sede Santo Domingo (438 personas), Universidad Regional Autónoma de los Andes (300 personas), Universidad Tecnológica Equinoccial (240 personas); Asociación de Ganaderos (1480 personas); Cámara de Comercio (625 personas), Asociación de Médicos (360 personas), Sindicato de Choferes (240 personas); Salón de la Ciudad (600 personas), Recinto Ferial Dr. Alfonso Torres Ordoñez (4000 personas), Instituto Tecnológico Superior Tsáchilas (170 personas).

Otro elemento importante es que Santo Domingo posee calles y avenidas que conectan un amplio rango de establecimientos, sin necesidad de recorrer largos trayectos entre uno y otro: desde donde se ofrecen prendas de vestir y zapatos hasta sitios de expendio de alimentos y bebidas; los valores por los servicios o productos varían según el establecimiento y la necesidad manifestada por el consumidor. Este recorrido va desde la Y del Indio Colorado hasta la avenida Quito.

La movilización en buses urbanos es posible gracias a la existencia de unidades con capacidad para el traslado de usuarios en poco tiempo de un barrio a otro o desde una zona céntrica. 


\section{Revista Iberoamericana \\ de las Ciencias Sociales y \\ Humanísticas}

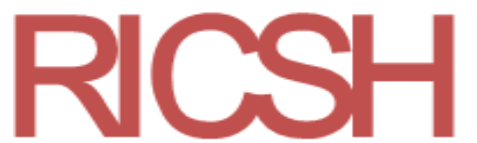

ISSN: $2395-7972$

Existen paseos peatonales que permiten la visibilidad de los productos exhibidos a la clientela, sus calles cuentan con parterres con plantas ornamentales. A su paso se pueden identificar también cafeterías y parques conectados a distancias cortas.

De acuerdo con Rojas (2019), otra alternativa de hacer turismo es la Vía Aventura. Está conformada por dos carriles diseñados para el desplazamiento peatonal y de bicicletas. La vía consta de 2.84 metros de ancho y está separada del tráfico motorizado por un parterrejardín de 78 centímetros. Existen cinco negocios de alquiler de bicicletas que ofrecen 16 paquetes turísticos de diversas categorías para avanzados, medios y novatos, cuyo costo va desde los 5 hasta los 20 dólares.

\section{Discusión}

En Santo Domingo hay suficientes elementos potenciales para ser considerada una ciudad turística. Las actividades turísticas que se evidencian sobre todo tienen que ver con alimentos y bebidas, alojamiento, operación e intermediación, parques y atracciones estables. En la ciudad se han asentado pobladores de las diferentes provincias del Ecuador, por lo que existen establecimientos con una oferta gastronómica variada, que reconoce la cultura y tradición del lugar natal de los pobladores asentados en el territorio.

Para determinar el potencial de un territorio es necesario emplear métodos que permitan valorar los recursos y atractivos, según lo indicado por Mikery y Pérez (2014). La provincia de Santo Domingo posee 86 atractivos dentro de su inventario, de los cuales una gran mayoría están dentro de la jerarquía II, cuya característica principal es que permiten generar un interés a los visitantes que llegan a la zona por diversos motivos. Otro elemento importante es que la ciudad cuenta con abastecimiento de agua potable, alcantarillado, energía eléctrica, telefonía móvil y fija; vías que conectan a la provincia de Santo Domingo con el resto del país, lo que la convierte en un punto de conexión nacional; posee atención médica pública y privada; y se estima que se realizan 1754 eventos por año en 14 establecimientos.

Se considera que estos factores hacen de Santo Domingo un sector potencialmente apto para el turismo. El mercado debe responder a las exigencias de la demanda para generar una cultura de consumo y, a través de esta, fortalecer el nexo entre los visitantes y la comunidad receptora. 


\section{Revista Iberoamericana \\ de las Ciencias Sociales y \\ Humanísticas}

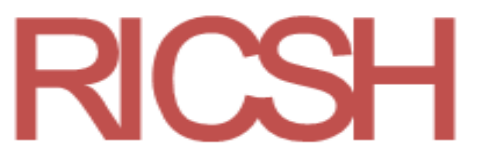

ISSN: $2395-7972$

\section{Conclusiones}

La existencia de actividades turísticas en Santo Domingo permite al visitante referir la zona y generar un incremento en la demanda, ya que sus preferencias y la satisfacción de sus necesidades suele ser la pieza clave para determinar el desarrollo de un territorio, tomando su potencial turístico como punto de partida para su evolución. Al aumentar la demanda, aumenta la oferta, lo que permite que la población local genere ingresos económicos.

Santo Domingo posee atractivos turísticos que marcan la identidad, cultura y tradiciones del territorio y de sus habitantes. Las agencias operadoras de turismo deben enfatizar en el diseño de paquetes, centrarse en dar a conocer estos atractivos y generar así un producto local; incrementar recorridos a pie, haciendo uso de los servicios de bares, cafeterías y parques conectados a distancias cortas. El trabajo mancomunado de los entes reguladores de turismo, la empresa pública, la empresa privada y la academia potenciará el desarrollo de la provincia.

\section{Futuras líneas de investigación}

La competitividad de un destino y su relación con la mercadotecnia debe ser objeto de estudio, puesto que se han identificado atractivos turísticos con diversas jerarquías ligados a empresas que se dedican a generar productos turísticos, identificando las necesidades y exigencias de la demanda. 


\section{Revista Iberoamericana \\ de las Ciencias Sociales y \\ Humanísticas}

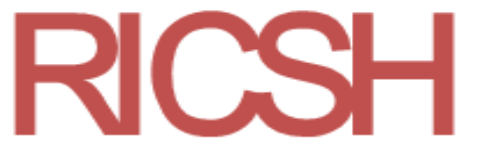

ISSN: 2395 - 7972

\section{Referencias}

Acle, R. y Montiel, A. (2018). Influencia de la gastronomía mexicana en el consumo étnico en España. Revista Interamericana de Ambiente y Turismo, 14(2).

Blacutt, M. (2013). El desarrollo local complementario. Un manual para la teoría en acción. Recuperado de http://www.eumed.net/libros-gratis/2013/1252/index.htm.

Brinckmann, W. y Wildgen, J. (2003). Desafíos para los estudiosos del turismo: La construcción de una sociedad inclusiva y del turismo accesible. Cuadernos de Turismo, (11), 41-58. Recuperado de https://revistas.um.es/turismo/article/view/19621.

Calle, S. (2019). Análisis de la restauración de Santo Domingo, caso: avenida La Lorena y Victor Lopez - Bombolí Sur. (Tesis de grado). Pontificia Universidad Católica del Ecuador, Santo Domingo. Recuperado de https://issuu.com/pucesd/docs/trabajo_de_titulaci_n_calle_esthela.

Castro, A. y Valarezo, J. (2019). Análisis de turismo de congresos y convenciones en Santo Domingo de los Colorados. (Tesis de grado). Pontificia Universidad Católica del Ecuador, Santo Domingo. Recuperado de https://issuu.com/pucesd/docs/trabajo_de_titulaci_n_castro_valarezo_.

Congreso Nacional. (29 de diciembre de 2014). Ley de Turismo. Registro Oficial de Ecuador, (supl. 733).

Gobierno Autónomo Descentralizado de Santo Domingo. (2014). Plan de Reordenamiento Territorial (PDOT) 2014-2019. Santo Domingo, Ecuador: Gobierno Autónomo Descentralizado de Santo Domingo.

Gobierno Autónomo Descentralizado de Santo Domingo. (2017). Producto I. Situación actual del turismo en Santo Domingo. Consultoría: estudio para la elaboración del plan de desarrollo turístico del cantón Santo Domingo. Santo Domingo, Ecuador: Gobierno Autónomo Descentralizado de Santo Domingo.

Hortua, N. (2011). Salvador Antón Clavé, Salvador. La urbanización turística: de la conquista del viaje a la reestructuración de la ciudad turística. Cuadernos de Geografía: Revista Colombiana de Geografía, 20(1). Recuperado de http://www.scielo.org.co/scielo.php?pid=S0121215X2011000100011\&script=sci_arttext\&tlng=en. 


\section{Revista Iberoamericana \\ de las Ciencias Sociales y \\ Humanísticas}

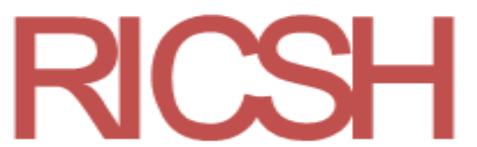

ISSN: 2395 - 7972

Instituto Nacional de Estadística y Censos [INEC]. (2010). Resultados del Censo 2010 de población y vivienda en el Ecuador. Fascículo provincial Sto. Domingo. Recuperado de https://www.ecuadorencifras.gob.ec/wp-content/descargas/Manulateral/Resultados-provinciales/santo_domingo.pdf.

Mikery, M. y Pérez, A. (2014). Métodos para el análisis del potencial turístico del territorio rural. Revista Mexicana de Ciencias Agrícolas, 5(núm. especial 9), 1729-1740.

Ministerio de Turismo. (2017). Guía metodológica para la jerarquización de atractivos y generación de espacios turísticos del Ecuador. Quito, Ecuador: Ministerio de Turismo. Recuperado de https://servicios.turismo.gob.ec/descargas/InventarioAtractivosTuristicos/Parte1_Gu iaMetodologicaInventarioGeneracionEspacioTuristico2017_2daEd.pdf.

Ministerio de Turismo. (2019). Consolidado nacional 2019. Actividades turísticas. Quito, Ecuador: Ministerio de Turismo.

Molina, S. (2000). Conceptualización del turismo. México: Limusa.

Moreno, A. y Valdivieso, J. (2017). Diseño y planificación de un encuentro nacional de turismo con periodicidad anual, dirigido al GAD Municipal del cantón Santo Domingo, año 2017. (Tesis de grado ). Pontificia Universidad Católica del Ecuador, Santo Domingo. Recuperado de https://issuu.com/pucesd/docs/disertaci_n_valdivieso_moreno.

Oliveira, S. (2011). La gastronomía como atractivo turístico de un destino: El turismo gastronómico en Mealhada - Portugal. Estudios y Perspectivas en Turismo, 20(3), 738-752. Recuperado de https://www.scienceopen.com/document?vid=86974d11445a-4cff-8167-0c7693a056b8.

Organización Mundial de Turismo [OMT]. (2016). Glosario de términos de turismo. Recuperado de https://www.unwto.org/es/glosario-terminos-turisticos.

Organización Mundial de Turismo [OMT]. (13 de febrero de 2019). Nuevo informe de la OMT sobre el turismo a pie. Comunicado de prensa, (PR190129). Recuperado de https://www.unwto.org/es/press-release/2019-02-13/nuevo-informe-de-la-omtsobre-el-turismo-pie.

Osorio, M. y Domínguez, J. (2019). Experiencias de turismo comunitario en el Área Natural Protegida del Nevado de Toluca, México: hacia la construcción de productos turísticos patrimoniales alternativos. Cuadernos de Desarrollo Rural, 16(83). 


\section{Revista Iberoamericana de las Ciencias Sociales y Humanísticas}

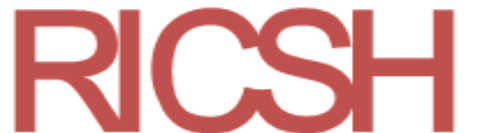

ISSN: 2395 - 7972

Recuperado de https://revistas.javeriana.edu.co/index.php/desarrolloRural/article/view/23237.

Quirola, P. (2019). Análisis de la restauración de Santo Domingo: Caso Avenida Venezuela. Santo Domingo: (Tesis de Grado). Escuela de Hotelería y Turismo. Pontificia Universidad Católica del Ecuador Sede Santo Domingo. Obtenido de https://issuu.com/pucesd/docs/trabajo_de_titulaci_n_quirola_patricia

Rivas, J. y Magadán, M. (2012). Planificación turística y desarrollo sostenible. Madrid, España: Septem Ediciones.

Rojas, V. (2019). Ciclovía: uso y percepciones desde la identidad. (Tesis de grado). Universidad Católica del Ecuador, Santo Domingo. Recuperado de https://issuu.com/pucesd/docs/trabajo_de_titulaci_n_201901_rojas_ver_nica_.

Valenzuela, E. y Coll, A. (2010). La construcción y evolución del espacio turístico de Acapulco (México). Anales de Geografía de la Universidad Complutense, 30(1), 163190. Recuperado de https://dialnet.unirioja.es/servlet/articulo?codigo $=3345378$.

Velarde, P. (2015). Una viajera alemana en Santo Domingo: Crónicas de la periodista Lilo Linke, sobre la antigua parroquia Santo Domingo de los Colorados 1956. Santo Domingo de los Colorados, Ecuador: Gobierno Provincial de Santo Domingo de los Tsáchilas.

Zhizpón, G. (2017). Plan de marketing para el desarrollo turístico de las rutas "Del Dulce y la Leche", "De la Aventura", "Del Cacao" y "Del Miya" de la provincia Tsáchila, año 2017. (Tesis de grado) Universidad Católica del Ecuador, Santo Domingo. Recuperado de https://issuu.com/pucesd/docs/trabajo_de_titulacion_bb6573799d6f8e. 


\section{Revista Iberoamericana \\ de las Ciencias Sociales y \\ Humanísticas}

ISSN: $2395-7972$

\begin{tabular}{|c|c|}
\hline Rol de Contribución & Autor (es) \\
\hline Conceptualización & $\begin{array}{l}\text { Igual: Ana Verónica Reza Segovia. Igual: Jenny Mabel } \\
\text { Villarroel Noboa. Igual: Julieta Johana Sánchez Mendoza. } \\
\text { Igual: José Marcelino Romero Gutiérrez }\end{array}$ \\
\hline Metodología & $\begin{array}{l}\text { Igual: Ana Verónica Reza Segovia. Igual: Jenny Mabel } \\
\text { Villarroel Noboa. Igual: Julieta Johana Sánchez Mendoza. } \\
\text { Igual: José Marcelino Romero Gutiérrez }\end{array}$ \\
\hline Software & $\begin{array}{l}\text { Igual: Ana Verónica Reza Segovia. Igual: Jenny Mabel } \\
\text { Villarroel Noboa. Igual: Julieta Johana Sánchez Mendoza. } \\
\text { Igual: José Marcelino Romero Gutiérrez }\end{array}$ \\
\hline Validación & $\begin{array}{l}\text { Igual: Ana Verónica Reza Segovia. Igual: Jenny Mabel } \\
\text { Villarroel Noboa. Igual: Julieta Johana Sánchez Mendoza. } \\
\text { Igual: José Marcelino Romero Gutiérrez }\end{array}$ \\
\hline Análisis Formal & $\begin{array}{l}\text { Igual: Ana Verónica Reza Segovia. Igual: Jenny Mabel } \\
\text { Villarroel Noboa. }\end{array}$ \\
\hline Investigación & $\begin{array}{l}\text { Igual: Ana Verónica Reza Segovia. Igual: Jenny Mabel } \\
\text { Villarroel Noboa. }\end{array}$ \\
\hline Recursos & $\begin{array}{l}\text { Igual: Ana Verónica Reza Segovia. Igual: Jenny Mabel } \\
\text { Villarroel Noboa. Igual: Julieta Johana Sánchez Mendoza. } \\
\text { Igual: José Marcelino Romero Gutiérrez }\end{array}$ \\
\hline Curación de datos & $\begin{array}{l}\text { Igual: Ana Verónica Reza Segovia. Igual: Jenny Mabel } \\
\text { Villarroel Noboa. Igual: Julieta Johana Sánchez Mendoza. } \\
\text { Igual: José Marcelino Romero Gutiérrez }\end{array}$ \\
\hline $\begin{array}{l}\text { Escritura - Preparación del } \\
\text { borrador original }\end{array}$ & $\begin{array}{l}\text { Principal: Ana Verónica Reza Segovia. Igual: Jenny Mabel } \\
\text { Villarroel Noboa }\end{array}$ \\
\hline Escritura - Revisión y edición & Ana Verónica Reza Segovia \\
\hline Visualización & Ana Verónica Reza Segovia \\
\hline Supervisión & $\begin{array}{l}\text { Igual: Ana Verónica Reza Segovia. Igual: Jenny Mabel } \\
\text { Villarroel Noboa. Igual: Julieta Johana Sánchez Mendoza. } \\
\text { Igual: José Marcelino Romero Gutiérrez }\end{array}$ \\
\hline Administración de Proyectos & $\begin{array}{l}\text { Igual: Ana Verónica Reza Segovia. Igual: Jenny Mabel } \\
\text { Villarroel Noboa. Igual: Julieta Johana Sánchez Mendoza. } \\
\text { Igual: José Marcelino Romero Gutiérrez }\end{array}$ \\
\hline Adquisición de fondos & $\begin{array}{l}\text { Igual: Ana Verónica Reza Segovia. Igual: Jenny Mabel } \\
\text { Villarroel Noboa. Igual: Julieta Johana Sánchez Mendoza. } \\
\text { Igual: José Marcelino Romero Gutiérrez }\end{array}$ \\
\hline
\end{tabular}


Revista Iberoamericana de las Ciencias Sociales y Humanísticas 